6-1998

\title{
Heritability of Expression of the 70kd Heat-shock Protein in Drosophila melanogaster and its Relevance to the Evolution of Thermotolerance
}

\author{
Robert A. Krebs \\ Cleveland State University, r.krebs@csuohio.edu \\ Martin E. Feder \\ University of Chicago \\ Jeehyun Lee \\ University of Chicago
}

Follow this and additional works at: https://engagedscholarship.csuohio.edu/scibges_facpub

Part of the Biology Commons, and the Genetics Commons

How does access to this work benefit you? Let us know!

\section{Publisher's Statement}

This is the accepted version of the following article: Krebs RA, Feder ME, Lee J. 1998.

Heritability of expression of the 70KD heat-shock protein in drosophila melanogaster and its relevance to the evolution of thermotolerance. Evolution 52(3):841-7., which has been published in final form at http://www.jstor.org/stable/2411278

\section{Recommended Citation}

Krebs RA, Feder ME, Lee J. 1998. Heritability of expression of the 70KD heat-shock protein in drosophila melanogaster and its relevance to the evolution of thermotolerance. Evolution 52(3):841-7.

This Article is brought to you for free and open access by the Biological, Geological, and Environmental Sciences Department at EngagedScholarship@CSU. It has been accepted for inclusion in Biological, Geological, and Environmental Faculty Publications by an authorized administrator of EngagedScholarship@CSU. For more information, please contact library.es@csuohio.edu. 


\title{
HERITABILITY OF EXPRESSION OF THE 70KD HEAT-SHOCK PROTEIN IN DROSOPHILA MELANOGASTER AND ITS RELEVANCE TO THE EVOLUTION OF THERMOTOLERANCE
}

\author{
Robert A. Krebs, 1,2 Martin E. Feder, ${ }^{1,3}$ AND JeEhyun Lee \\ ${ }^{1}$ Department of Organismal Biology and Anatomy, University of Chicago, 1027 East 57th Street, Chicago, Illinois 60637 \\ ${ }^{3}$ Committee on Evolutionary Biology, University of Chicago, 1027 East 57th Street, Chicago, Illinois 60637
}

\begin{abstract}
The principle inducible heat-shock protein of Drosophila melanogaster, Hsp70, contributes to thermotolerance throughout the entire life cycle of the species but may also reduce fitness in some life stages. In principle, selection might maximize the benefits of Hsp70 expression relative to its costs by adjusting the magnitude of Hsp70 expression for each life-cycle stage independently. Therefore we examined whether the magnitude of Hsp 70 expression varied during the life cycle and the relationship of this variation to several life-history traits. For 28 isofemale lines derived from a single natural population, estimates of heritable variation in Hsp70 expression ranged between 0.25 and 0.49 , and the association among variation in first- and third-instar larvae and in adults correlated highly. Thus, Hsp70 expression is genetically coupled at these developmental stages. A line engineered with extra copies of the hsp70 gene produced more Hsp70 and survived heat shock much better than did a control strain. Among natural lines, Hsp70 expression was only weakly related to tolerance of heat shock and to larva-to-adult survival and developmental time at permissive temperatures. Additionally, lines with high adult survival developed slowly as larvae, which is a possible trade-off. These and other findings suggest that trade-offs may maintain quantitative variation both in heatshock protein expression and in life-history traits that associate with thermotolerance.
\end{abstract}

Key words.-Developmental time, genetics, high temperature, stress, trade-offs.

Received April 22, 1997. Accepted March 6, 1998.

Two phenotypic traits are genetically correlated or coupled when variation in one or more genes affects both traits. Genetic correlations can be evolutionarily significant when pleiotropic effects on coupled traits oppose the increase of a beneficial trait or maintain a deleterious trait that selection would otherwise eliminate (Atchley 1987; Barton 1990; Houle 1991; Arnold 1994). Such coupled traits might act at different times during development (Christiansen 1990; Arnold 1992) or affect multiple aspects of morphology (Cowley and Atchley 1988; Gu and Zera 1996) or energy allocation (Clark 1990). For example, genetic coupling may constrain the evolution of large adult size in insects even though size and fecundity are highly correlated (Reeve and Robertson 1953; Partridge and Farquhar 1983). In this case, increasing size requires lengthening the mortality-prone larval period, which will more than outweigh the benefits of large adult size for fitness (Zwaan et al. 1995; Nunney 1996).

In studies of genetic coupling, as in the foregoing example, the discrete genetic basis of the coupling is rarely understood (Pigliucci 1996). An initial analysis of quantitative variation of expression of the heat-shock protein Hsp70 in Drosophila (Krebs and Feder 1997a), however, suggested that we could investigate genetic coupling with respect to a single gene product. Accordingly, we have characterized variation in Hsp70 expression and its consequences at various stages in the Drosophila life cycle to elucidate the genetic and functional bases for coupling across the development of this holometabolous insect.

In Drosophila, at least 10 nearly identical genes encode Hsp70 (Ish-Horowicz et al. 1979), a protein that contributes to inducible thermotolerance at several developmental stages

\footnotetext{
${ }^{2}$ Present address: Department of Biological, Geological and Environmental Sciences, Cleveland State University, 2399 Euclid Avenue, Cleveland, Ohio 44115; E-mail: rkrebs@biology.csuohio.edu.
}

(Feder et al. 1996). However, Hsp70 can inhibit growth, reduce thermotolerance, and be toxic at high concentrations (Feder et al. 1992; Krebs and Feder 1997b). Thus, these opposing effects may constitute an evolutionary trade-off. The need for inducible thermotolerance likely varies among developmental stages, with larvae and pupae especially prone to high temperatures because they occupy necrotic fruit, while adults may minimize thermal stress through their welldeveloped capacity for microhabitat selection and locomotion (Jones et al. 1987; Feder et al. 1997a,b). We asked, therefore, whether Hsp70 expression is modified in the various developmental stages according to its costs and benefits, or whether its common genetic basis constrains variation among stages. We explored this question with quantitative genetic techniques by examining isofemale lines founded from a single natural population in two successive years; these lines can vary naturally in Hsp70 expression and thermotolerance (Krebs and Feder 1997b). We also examined lines genetically engineered to differ in hsp70 copy number, and thus in expression of Hsp70 (Welte et al. 1993).

\section{Materials and Methods}

\section{Natural Lines}

We reared Drosophila from peaches collected in Garwood Orchards, LaPorte, Indiana, $41^{\circ} 36.4^{\prime} \mathrm{N}, 86^{\circ} 43.2^{\prime} \mathrm{W}$ in August 1996. Flies emerged from the fruit in a large population cage at room temperature after more than four days in the laboratory. Therefore, most individuals were larvae when captured. Each day all emerging adults were aspirated from the cage, anesthetized with $\mathrm{CO}_{2}$, and one male and one female were placed as pairs in vials containing $12 \mathrm{~mL}$ of a yeast, cornmeal, molasses, and agar medium. Pairs were transferred to new vials after four days to increase population size of isofemale lines rapidly. Male offspring were used for species 
identification (28 of 29 lines were $D$. melanogaster and one line was $D$. simulans). Subsequent generations reared from a minimum of four such vials. With rapid expansion of populations at low larval density, relatedness among individuals within the same line is $3 / 4$, and between lines the relatedness is $1 / 2$ for purely additive traits (Hoffmann and Parsons 1988). Under this rearing regime, drift effects are small and relatedness changes slowly (Hoffmann and Parsons 1988). Although selection due to a novel laboratory environment will, over time, affect fitness and correlated traits (Dobzhansky and Spassky 1947; Ayala 1965; Service and Rose 1985), in a noncompetitive environment effects of both adaptation and inbreeding are minor compared to those when population size is large (Latter and Mulley 1995).

Hsp70 expression was measured on first-generation offspring of wild-caught flies at two developmental stages: thirdinstar "wandering-phase" larvae (see below for one exception) and newly eclosed adults. At each stage, 12 full-sib individuals from each line were sampled separately by placing each in a microfuge tube, which was placed in a water bath for $1 \mathrm{~h}$ at $36^{\circ} \mathrm{C}$, for $1 \mathrm{~h}$ at $25^{\circ} \mathrm{C}$, and then in liquid $\mathrm{N}_{2}$. Larvae were picked from the sides of cultures without anesthesia; adults were anesthetized briefly with $\mathrm{CO}_{2}$ but recovered before the heat shock. First-instar larvae in the fourth laboratory generation were sampled similarly. To produce first-instar larvae for these measurements, adults of the previous generation were transferred to oviposition chambers containing a removable $5-\mathrm{cm}$ petri dish lid filled with medium. Eggs were laid and first-instar larvae were collected from this surface, with 40-45 larvae transferred to each of five tubes per line. All tubes contained $10 \mu \mathrm{L}$ phosphatebuffered saline (PBS) to prevent desiccation. Hsp70 concentration in a lysate prepared from the contents of each tube was determined by enzyme linked immunosorbent assay (ELISA), which has been described elsewhere (Welte et al. 1993; Feder et al. 1996; Krebs and Feder 1997a). The ELISA signal is proportional to Hsp70 concentration in the lysates and is expressed as a percentage of a standard signal, that for a lysate of Drosophila S2 cells in tissue culture that have been exposed to $36.5^{\circ} \mathrm{C}$ for $1 \mathrm{~h}$ and $25^{\circ} \mathrm{C}$ for $1 \mathrm{~h}$ before lysis.

Three traits related to fitness were measured for each line: larval developmental time, survival from first-instar larva to adult at $25^{\circ} \mathrm{C}$, and thermotolerance of adults. To measure these traits, 40 first-instar larvae were placed on $8 \mathrm{~mL}$ medium in each of five vials per line, one vial per line each day, and reared to adulthood at a constant $25^{\circ} \mathrm{C}$. Flies emerging from these vials were censused daily until no more eclosed. Thermotolerance was assayed on a subset of the eclosing adults, which controlled for larval density, a trait that may affect thermotolerance (Loeschcke et al. 1994).

To measure thermotolerance of adults, freshly eclosed flies from each line were anesthetized and distributed to fresh food vials, 10 males and 10 females to a vial. We collected flies from each line on five consecutive days, preferentially using those adults that emerged early. Excess flies were scored for developmental rate, but discarded, ensuring that adults varied in age by no more that $24 \mathrm{~h}$. In a few cases, a shortfall occurred. The affected line was omitted that day, and a replacement vial was prepared on a later day. Flies were heattreated one day after collection. Vials of flies were capped with a moistened stopper above a cotton plug, inverted in a rack with vials evenly spaced, immersed in a water bath for $1 \mathrm{~h}$ at $36^{\circ} \mathrm{C}$, placed in a $25^{\circ} \mathrm{C}$ incubator for $1 \mathrm{~h}$, and then immersed in a water bath for $1 \mathrm{~h}$ at $39.5^{\circ} \mathrm{C}$. Data were the proportion that could walk $24 \mathrm{~h}$ after this treatment. Effect of block variation in sampling days was considered for determining line means in adult heat-shock tolerance.

\section{Hsp70 Copy-Variation Lines}

Welte et al. (1993) constructed two pairs of lines that differ in the number of $h s p 70$ gene copies; 12 gene copies were added to create an "extra-copy" line. The procedure that duplicates the initial insert in one chromatid simultaneously deletes the insert in another, thereby creating an "excision" strain that has only wild-type copy number but contains an insert at the identical site of transgene integration. Initial experiments used the line with an insert on chromosome II, and more extensive experiments followed on a second line with an insert on chromosome III (Welte et al. 1993).

Assay conditions for adult thermotolerance were similar to those used for the natural lines. Adults from the excision and extra-copy strains were reared in half-pint bottles. For the chromosome II lines, males and females that emerged within a $24 \mathrm{~h}$ period were separated by $\mathrm{CO}_{2}$ anesthesia, placed in groups of 15-20, and given one of three treatment regimes $3 \mathrm{~h}$ after collection: $1 \mathrm{~h}$ at $36^{\circ} \mathrm{C}, 1 \mathrm{~h}$ at $25^{\circ} \mathrm{C}$, and $1 \mathrm{~h}$ at $39^{\circ} \mathrm{C}$; $3 \mathrm{~h}$ or $24 \mathrm{~h}$ after collection: $1 \mathrm{~h}$ at $36^{\circ} \mathrm{C}, 1 \mathrm{~h}$ at $25^{\circ} \mathrm{C}$, and 1 $h$ at $39.5^{\circ} \mathrm{C}$. For the chromosome III lines, adults were similarly collected and treated for $1 \mathrm{~h}$ at $36^{\circ} \mathrm{C}, 1 \mathrm{~h}$ at $25^{\circ} \mathrm{C}$ and $1 \mathrm{~h}$ at $39^{\circ} \mathrm{C}$ across a range of ages. The youngest adults were less than one day old and the oldest were four to five days old.

\section{Statistics}

Genetic variance components and intraclass correlations were computed from a random effect ANOVA as recommended in Hoffmann and Parsons (1988); the additive genetic variance component, $\mathbf{S}_{\mathrm{A}}{ }_{\mathrm{A}}=\left(\mathrm{MS}_{\text {line effect }}-\mathrm{MSE}\right) /($ harmonic mean sample size), and the intraclass correlation, $t=S^{2}{ }_{A}^{\prime}$ $\left(\mathrm{S}_{\mathrm{A}}^{2}+\mathrm{MSE}\right)$. The intraclass correlation estimates the proportion of the total variance that is due to genetic differences between groups of individuals, and its significance was tested from the line effect in the ANOVA. Measurement of Hsp70 variation in wandering-phase third-instar larvae and adults was on single individuals that were full siblings. For these, we estimated the broad-sense heritability $\left(h^{2}\right)$ for Hsp70 expression in these stages as twice the intraclass correlation. This estimate is a maximum (Falconer 1981). Hsp70 in firstinstar larvae was measured on groups of 40 from which $t$ (the intraclass correlation) also may be obtained, but this group measurement may bias estimation of $h^{2}{ }_{b}$ upward because it decreases within vial variance (Krebs and Loeschcke 1997). Estimates of $h_{b}^{2}$ for larva-to-adult survival at $25^{\circ} \mathrm{C}$, developmental time and adult thermotolerance may contain similar biases. Pooling many first-instar larvae, however, was necessary to obtain sufficient protein for ELISA, and group measurement is required to obtain proportions in estimates of survival. In all experiments, heat-shock replicates were treated on different days in a water bath, but bath temperatures varied by no more than $0.1^{\circ} \mathrm{C}$. Variation among several 
TABLE 1. Means ( \pm 1 SE), intraclass correlations and estimates of the broad-sense heritability for Hsp70 level after heat shock (as a percent of standard) of first-instar larvae, wandering-phase third-instar larvae, and adults and of larva-to-adult survival at constant $25^{\circ} \mathrm{C}$, larval developmental time, and adult tolerance of heat shock.

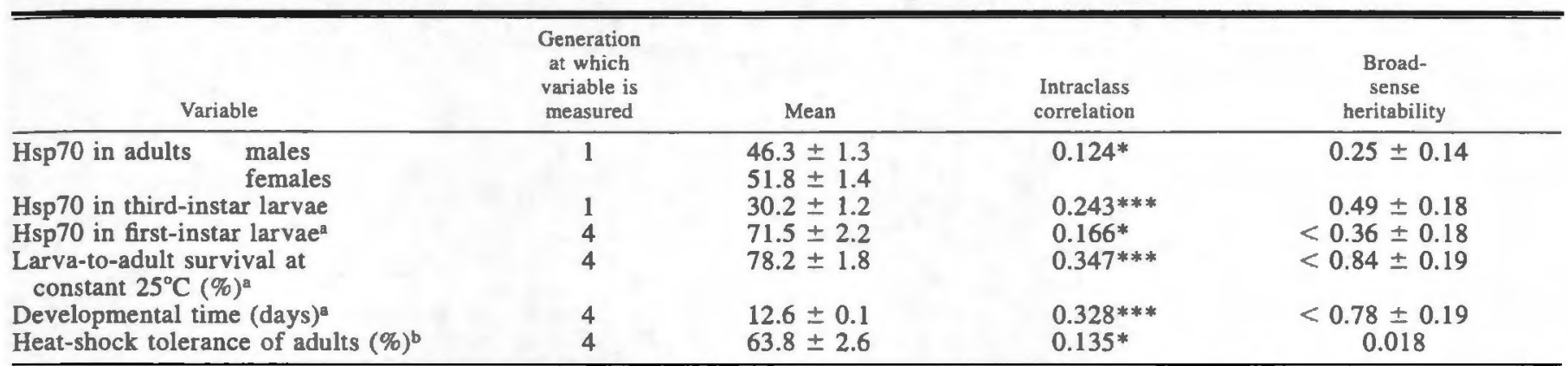

${ }^{2}$ Estimated from groups thereby underrepresenting error variation.

b Group measurement effect on variance factored assuming complete density-dependence of error variation (Krebs and Loescheke 1997).

$* P<0.05, * * * P<0.001$ (ANOVA).

ELISAs potentially contributed experimental variation that was factored in blocks for genetic analyses. One ELISA failed, and samples of these wandering-phase third-instar larvae were replaced by third-generation offspring. Results were similar with or without these replacement larvae; reported results contain these data.

Transformation was necessary for analysis of survival and developmental time. Proportions were arcsine-square root transformed. Developmental time was determined as the mean of males and of females per vial each calculated as $\log ^{-1}$ of the log-transformed eclosion time per individual. Therefore the proportion or mean for each vial was the unit of replication.

To assess correlation coefficients among traits, tablewide significance levels were adjusted by the sequential Bonferroni procedure (Rice 1989) based on $\mathbf{k}=9$ correlations, a number chosen because the correlation coefficients most important to the hypotheses tested were: those among the three measurements of Hsp70 concentration at the various developmental stages; those among the three fitness related traits, larva-to-adult survival at $25^{\circ} \mathrm{C}$, larval developmental time, and adult thermotolerance; and those correlations between the fitness variables and Hsp70 concentration, which are expected to be similar independent of the particular estimate used for Hsp70.

\section{RESUlts \\ Natural Lines}

Developmental stages varied in the concentration of Hsp70 $(P<0.001)$ after heat shock (Table 1$)$. On average, first- instar larvae produced more Hsp70 per unit protein than did young adults, and both first-instar larvae and adults produced more than wandering-phase third-instar larvae. Adult females produced more Hsp70 than males $(P<0.05)$.

Lines varied in Hsp70 expression and in the fitness-related traits. Intraclass correlations (Table 1) indicated that Hsp70 variation in all three life-cycle stages, larval survival and developmental time under the benign treatment condition $\left(25^{\circ} \mathrm{C}\right)$, and adult thermotolerance have important genetic components. Estimates of the broad-sense heritability from the intraclass correlations differed almost by a factor of two between third-instar larvae and adults $(0.49$ to 0.25$)$, but the large standard errors typical of these analyses prevented meaningful tests of significance between estimates. Broadsense heritabilities of the fitness traits as well as of $\mathrm{Hsp70}$ expression of first-instar larvae originated from group measurements, and therefore are maxima. Because group effects for threshold traits are almost directly proportional to group size (Krebs and Loeschcke 1997), the estimate of heritability for adult thermotolerance is low $\left(h^{2}{ }_{b}=0.018\right)$, and it accounts for the reduction in interindividual variance due to using many flies to obtain proportional data (harmonic mean of 17.4 adults per replicate vial).

Hsp70 expression correlated positively among family means for the three life-cycle stages (Table 2), and although highest between first- and third-instar larvae, coefficients did not differ statistically ( $P>0.05$ for all three comparisons). Lines differed more than twofold in larval Hsp70 concentration, with means ranging from $50 \%$ to $>100 \%$ of the

TABLE 2. Correlation matrix among measurements on Hsp70 level after heat shock in 28 lines, and on the fitness related traits, larvato-adult survival at constant $25^{\circ} \mathrm{C}$, larval developmental time, and adult tolerance of heat shock. The three fitness traits were measured on the same individuals and therefore correlations among these traits are phenotypic.

\begin{tabular}{|c|c|c|c|c|c|}
\hline Variables & $\begin{array}{l}\text { Hsp70 } \\
\text { third } \\
\text { instars }\end{array}$ & $\begin{array}{l}\text { Hsp70 } \\
\text { first } \\
\text { instars }\end{array}$ & $\begin{array}{l}\text { Survival } \\
\text { at } 25^{\circ} \mathrm{C}\end{array}$ & $\begin{array}{l}\text { Develop. } \\
\text { time }\end{array}$ & $\begin{array}{l}\text { Heat } \\
\text { shock } \\
\text { adults }\end{array}$ \\
\hline Hsp70 in adults & $0.47^{*}$ & $0.52 *$ & 0.18 & 0.16 & 0.16 \\
\hline Hsp70 in first-instar larvae & & & 0.20 & 0.12 & 0.03 \\
\hline Larva-to-adult survival at constant $25^{\circ} \mathrm{C}$ & & & & $-0.50 *$ & -0.09 \\
\hline Developmental time & & & & & $0.64 * *$ \\
\hline
\end{tabular}

${ }^{*} P<0.05, * * P<0.01,{ }^{* * *} P<0.001$ (tablewide significance using the sequential Bonferroni procedure). 


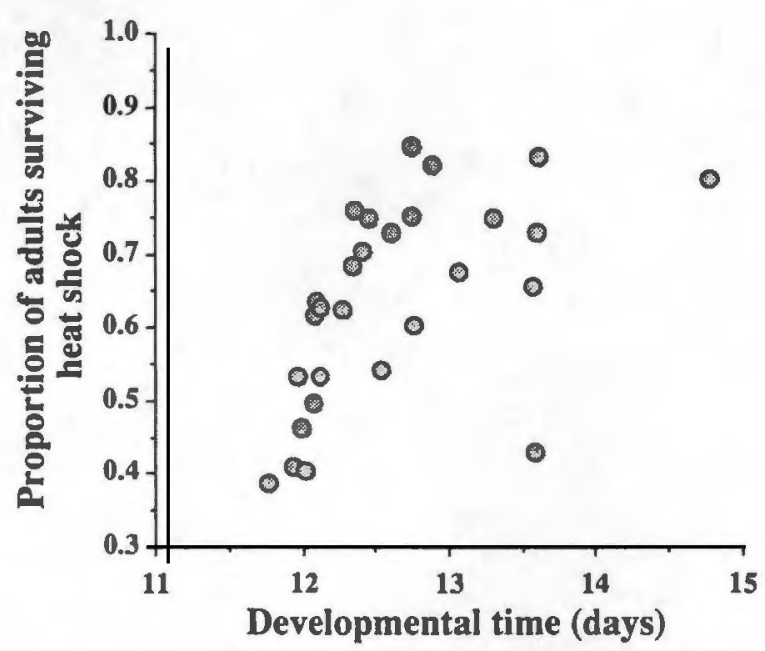

FIG. 1. Mean tolerance of adults in each isofemale line to the thermal stress treatment, $1 \mathrm{~h}$ at $36^{\circ} \mathrm{C}, 1 \mathrm{~h}$ at $25^{\circ} \mathrm{C}$, and $1 \mathrm{~h}$ at $39.5^{\circ} \mathrm{C}$ plotted against mean egg-to-adult developmental time.

standard in first-instars and from $20 \%$ to $40 \%$ in third-instars. Adults differed relatively less, with lines ranging from $40 \%$ to $60 \%$ of the standard. Because these correlations do not adequately test for developmental variation in Hsp70 expression, all data on Hsp70 concentration were pooled and tested in a single ANOVA to obtain tests for statistical interaction between the main effects, line (tested against MSE; $F_{27.358}=4.9, P<0.001$ ) and life-cycle stage (tested against the line-by-stage interaction; $F_{2,54}=460, P<0.001$ ). Lines varied similarly at all stages $\left(F_{2,358}=1.06, \mathrm{NS}\right)$, indicating that selection for Hsp70 expression at one developmental stage will alter Hsp70 expression throughout development.

Although the fitness measurements were not correlated with $\mathrm{Hsp} 70$ expression, larva-to-adult survival at $25^{\circ} \mathrm{C}$ correlated negatively with larval developmental time, and adult thermotolerance correlated positively with developmental time (Table 2). Thus, individuals from more rapidly developing lines survived better in the absence of heat shock but more poorly in the face of thermal stress (Fig. 1).

\section{Hsp70 Copy-Variation Lines}

After heat shock, Hsp70 concentrations in chromosome II insertion adults carrying extra copies of $h s p 70$ exceeded those for flies from the excision control strain (Fig. 2a). Males and females of the same strain did not differ. Extra-copy adults also survived heat shock in higher proportions than did adults from the excision line $\left(F_{1,42}=23.7, P<0.001\right)$ at all treatments (Fig. 2b). More females survived than males ( $F=6.0, P<$ 0.05 ), and much larger line differences occurred in males than in females (line-by-sex interaction, $F=8.5, P<0.01$ ). Although the different stress treatments greatly affected survival $\left(F_{2,42}=148, P<0.001\right)$, the lack of any interaction effects with treatment indicated robust line and sex effects for adult thermotolerance.

The same factors affected thermotolerance in the chromosome III insertion strains (Fig. 3). Survival declined in older flies $(P<0.001$ for males and females). Males from the extracopy strain survived heat shock in higher proportions than did
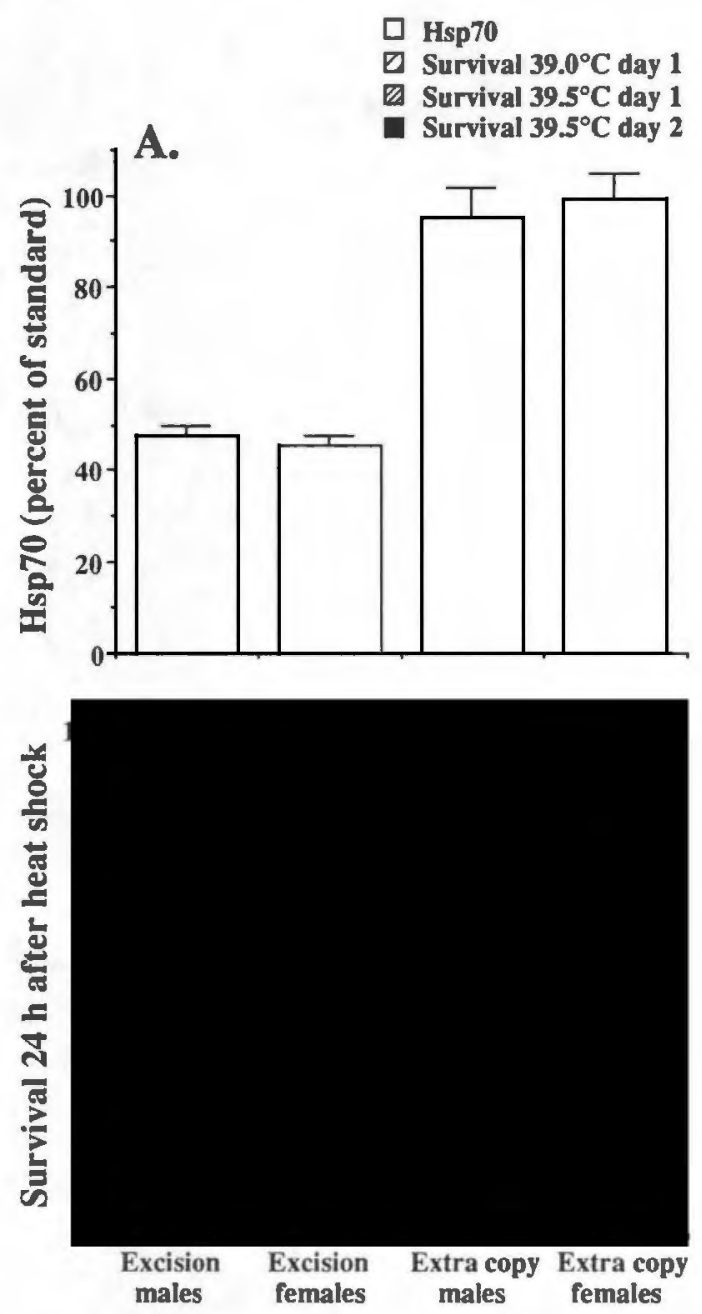

Fic. 2. Mean Hsp70 concentration as a percent of a standard (a) and mean survival after heat shock (b) for adults of a pair of transgenic strains (insertions in chromosome II), an hsp70 extra-copy strain and its excision control (bars are $1 \mathrm{SE}$ ). Treatment of all flies included $1 \mathrm{~h}$ at $36^{\circ} \mathrm{C}$ followed by $1 \mathrm{~h}$ at $25^{\circ} \mathrm{C}$ after which individuals were frozen for Hsp 70 analysis or received heat shocks of $39^{\circ} \mathrm{C}$ or $39.5^{\circ} \mathrm{C}$ for $1 \mathrm{~h}$. One-day-old flies were treated the same day of collection (less than 4-28 h posteclosion) and two-day-old flies the day after (28-52 h posteclosion).

males from the excision line (Fig. 3a, $F_{1,123}=7.4, P<0.01$; and separated by day, effects were significant between strains for males aged 1.0-1.5, 1.5-2.0 and 2.0-2.5 days). Females of the two strains differed much less in thermotolerance (Fig. 3b, $\left.F_{1,125}=0.4, \mathrm{NS}\right)$. Because all young flies $(<1.0$ day old $)$ survived and most flies over 2.5 days old died, these age groups were not informative of the effect of increased Hsp70 at the treatment used, although they indicate the magnitude of effect adult age had on thermotolerance.

\section{DisCUSSION}

Hsp70 concentration after heat shock varied during development. First-instar larvae produced the most Hsp70 per unit total organismal protein, followed by adults and then wandering-phase third-instar larvae. This variation in itself may signify little more than the differing size of organs in 


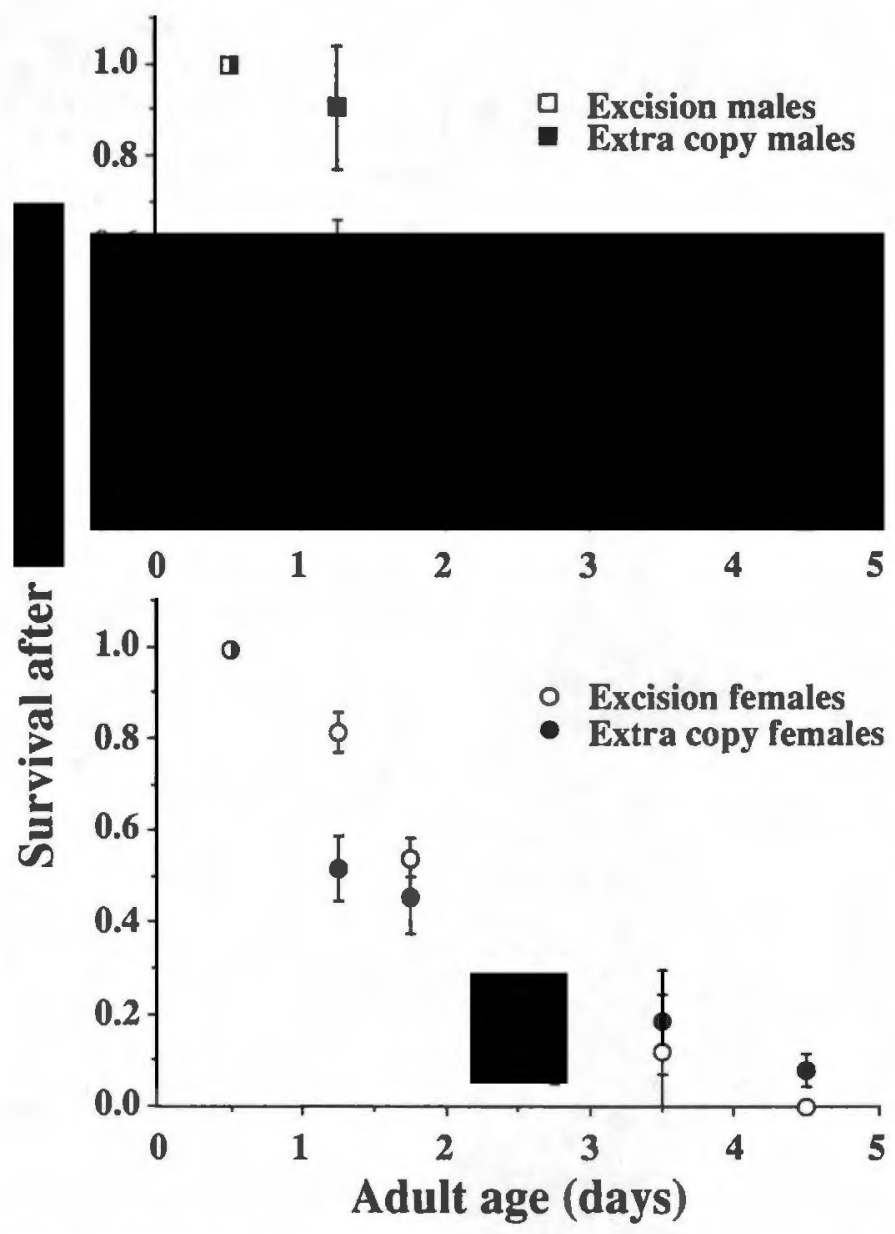

Fig. 3. Mean survival after heat shock for adult males (a; squares) and females (b; circles) of a pair of transgenic strains, an hsp70 extra-copy strain (filled symbols) and its excision control (open symbols), which have the insertion in chromosome III. Bars indicate \pm I SE. Treatment of all flies was $1 \mathrm{~h}$ at $36^{\circ} \mathrm{C}$ followed by $1 \mathrm{~h}$ at $25^{\circ} \mathrm{C}$ and $1 \mathrm{~h}$ at $39^{\circ} \mathrm{C}$. The range in ages of each group of flies was $<1.0$ day old, 1.0-1.5 days old, $1.5-2.0$ days old, $2.0-2.5$ days old, 2.5-3.0 days old, 3.0-4.0 days old, and 4.0-5.0 days old.

the developmental stages under study. Fat body, for example, which is especially abundant in third-instar larvae, expresses Hsp70 more slowly and less intensely than most other tissues (Krebs and Feder 1997c). Similarly, differences between male and female gonadal tissue in Hsp70 expression (Palter et al. 1986) may account for the greater Hsp 70 concentrations in lysates of adult females than in males. More importantly, at each developmental stage the 28 isofemale lines derived from the natural population differed significantly and consistently in Hsp 70 concentrations after a standard heat shock. Potentially the common environment of the third-instar larvae and adults, which were full-sibs, could bias genetic correlations between these two stages, but no statistical interaction occurred in comparisons among lines at any developmental stage. Analysis of first-instar larvae postdated that of the other stages by two generations. This finding corroborates an earlier study of intrapopulation variation in $\mathrm{Hsp} 70$ and again demonstrates that, despite the notably highly conserved coding sequence and primitive origin of $h s p 70$ genes
(Gupta 1990), Hsp70 expression can vary within a single population of wild organisms.

At each developmental stage, the broad-sense heritability for Hsp70 expression is moderate or high. Given these heritability estimates, Hsp70 expression should respond rapidly to selection. Such a response can be both beneficial and deleterious, as is especially evident in engineered lines in which variation in $\mathrm{Hsp} 70$ exceeds that in nature. In these extra-copy lines, thermotolerance is greater than for control strains, which possess a wild-type complement of genes: in early embryos (Welte et al. 1993), in late third-instar larvae and early pupae (Feder et al. 1996), and in adult males (Figs. 2, 3). In these same lines, however, elevated Hsp70 lengthens development and reduces survival of growing larvae (Krebs and Feder 1997b) and the developing imago two to three days into pupation (R. Krebs, unpubl. data). Patterns are similar, although less marked, among isofemale lines that differ in Hsp70 expression (Krebs and Feder 1997a) and between annual collections of a single natural population (1995 collection: survival, 87\%, Hsp70, 45\%; 1996 collection: survival, $78 \%$, Hsp70, 71.5\%).

Because relative $\mathrm{Hsp} 70$ expression at any given stage is closely coupled to expression at other stages, selection on any one stage will similarly alter expression throughout the life cycle. In other words, were selection to increase Hsp70 expression at a particular stage at which it is most needed, Hsp70 expression also would increase at other stages where it may have deleterious side effects. Consequently, evolutionary responses to environmental change will depend on the overall consequences of altered Hsp70 expression on the entire life cycle, and fitness consequences at one developmental stage may trade off against fitness consequences at another. Trade-offs are frequently invoked to explain the maintenance of genetic variation in natural populations (Lande 1982; Stearns 1992), particularly with respect to lifehistory phenotypes (e.g., longevity and early fecundity; Rose and Charlesworth 1981; Partridge and Fowler 1992; Leroi et al. 1994). The present study, however, demonstrated no discrete relationship among $\mathrm{Hsp} 70$ and life-history traits in the natural lines. The growing analysis of differential effects of Hsp70 on various life-cycle stages (Feder and Krebs 1997) and the strong correlation in expression among these stages nonetheless suggest that trade-offs may maintain quantitative variation in the expression of this protein.

The relationship between slow larval development and high adult thermotolerance may also represent a trade-off (Table 2), but the precise basis is unclear. In contrast, the negative correlation $(-0.50)$ between developmental time and survival indicates that more faster-developing larvae survive to adult, which represents a positive life-history relationship. Slow development suggests a reduced metabolism (Parsons 1996), and metabolic variation affects tolerance of many chemical stresses and of desiccation (Hoffmann and Parsons 1991; Parsons 1996). In D. buzzatii, however, adult thermotolerance and larval developmental time are not related (Krebs and Loeschcke 1995), and adult tolerance is not correlated with adult basal metabolic rate (Loeschcke et al. 1997). This difference between $D$. melanogaster and $D$. buzzatii may be species specific. Alternatively, overlap in the individuals used to measure both larval developmental time 
and survival to adult could have biased results, but systemic line differences are likely only when developmental times increased greatly, as may occur with inbreeding. Slow development correlated with lower larva-to-adult survival (Table 2), but reanalysis of the relationship between larval developmental time and adult thermotolerance after removing slowly developing (presumably inbred) lines increased the correlation (to 0.78 for 21 lines, $P<0.001$ ). This change in a correlation after removing some lines shows a common effect of inbreeding on life-history relationships in isofemaleline analyses; inbreeding reduces performance in all traits, causing positive genetic associations. Thus isofemale-line tests for trade-offs generally are conservative.

This conservative nature of tests for genetic correlations similarly increases the difficulty for identifying positive trait interactions, particularly when pairwise relationships are a part of a more complex matrix of trait interactions (Kirkpatrick 1996). Many traits may affect variation in thermotolerance, of which Hsp70 expression is only one. Among lines, adult thermotolerance and $\mathrm{Hsp} 70$ expression are associated only weakly (Table 2 ), but, given the relationship evident in engineered lines, the weak association may refiect lower genetic variation in either or both traits rather than a true lack of a relationship between $\mathrm{Hsp} 70$ and thermotolerance. Lines in the more recent collection varied less in Hsp70 expression than did those the year before, as the intraclass correlation on first-instar larvae was 0.24 in 1995 (Krebs and Feder 1997a) but only 0.17 in 1996 . Additionally, the range of expression is less in adults (highest line/lowest line $=1.5$ ) than in larvae (highest line/lowest line $=2.0$ ) in the 1996 data. As the direction of the thermotolerance-Hsp70 association is consistent between natural and engineered lines, a relationship likely exists between these traits. Such weak links to fitness can be evolutionarily important (Wright 1931).

In conclusion, Hsp70 expression varies genetically and is conserved across several life-cycle stages. Considerable prior work with natural (Krebs and Feder 1997a) and genetically engineered (Welte et al. 1993; Feder et al. 1996; Krebs and Feder 1997b) lines establishes that variation in Hsp70 expression can have both positive and negative consequences. Surprisingly, such consequences were weak or undetectable in the present study. One possible explanation for the discrepancy is that limited genetic variation in our natural lines can at times obscure these consequences; another is that uncontrolled year-to-year changes in the wild population from which our natural lines were derived at times override the interaction between Hsp 70 expression and other traits (Pease and Bull 1988; Charlesworth 1990). To examine these possible explanations, long-term studies of variation in Hsp70 expression and other traits in the wild are presently underway. Hopefully, this work will elucidate the pleiotropic and antagonistic effects of $\mathrm{Hsp} 70$ variation.

\section{ACKNOWLEDGMENTS}

We thank N. Cartaño and J. Kim for assistance collecting data, R. Snook and G. Gilchrist for critically reading the manuscript, and the proprietors of Garwood Orchards, LaPorte, Indiana, for permission to work on their property. Research was supported by National Science Foundation grants IBN94-08216 and BIR94-19545 and the Louis Block Fund of the University of Chicago.

\section{Literature Cited}

ARNOLD, S. J, 1992. Constraints on phenotypic evolution. Am. Nat. 140:S85-S107.

1994. Multivariate inheritance and evolution: a review of the concepts. Pp. 17-48 in C. R. B. Boake, ed. Quantitative genetic studies of behavioral evolution. Univ. of Chicago Press, Chicago.

AtChLEY, W. R. 1987. Developmental quantitative genetics and the evolution on ontogenies. Evolution 41:316-330.

AYALA, F. J. 1965. Evolution of fitness in experimental populations of Drosophila serrata. Science 150:903-905.

Barton, N. H. 1990. Pleiotropic models of quantitative variation. Genetics 124:773-782.

Charlesworth, B. 1990. Optimization models, quantitative genetics, and mutation. Evolution 44:520-538.

Christiansen, F. B. 1990. Genetic comparisons of life stages in natural populations of Zoarces viviparus. Pp. 287-305 in J. Adams, A. Hermalin, D. Lam, and P. Smouse, eds. Convergent issues in genetics and demography. Oxford Univ. Press, New York.

ClaRK, A. G. 1990. Genetic components of variation in energy storage in Drosophila melanogaster. Evolution 44:637-650.

CowlEy, D. E., AND W. R. A TCHLEY. 1988. Quantitative genetics of Drosophila melanogaster. II. Heritabilities and genetic correlations between sexes for head and thorax traits. Genetics 119: 421-433.

Dobzhansky, Th., AND B. Spassky. 1947. Evolutionary changes in laboratory cultures of Drosophila pseudoobscura. Evolution $1: 191-216$.

FALCONER, D. S. 1981. Introduction to quantitative genetics. $2 d$ ed. Longman, New York.

Feder, J. H., J. M. Rossi, J. Solomon, N. Solomon, AND S. LindQUIST. 1992. The consequences of expressing hsp70 in Drosophila cells at normal temperatures. Genes Dev. 6:1402-1413.

FEDER, M. E., AND R. A. KREBS. 1997. Ecological and evolutionary physiology of heat-shock proteins and the stress response in Drosophila: complementary insights from genetic engineering and natural variation. Pp. 155-173 in R. Bijlsma and V. Loeschcke, eds. Environmental stress, adaptation and evolution. Birkäuser Verlag, Basel, Switzerland.

Feder, M. E., N. V. Cartaño, L. Milos, R. A. Krebs, and S. L. LINDQUIST. 1996. Effect of engineering $\mathrm{Hsp} 70$ copy number on Hsp70 expression and tolerance of ecologically relevant heat shock in larvae and pupae of Drosophila melanogaster. J. Exp. Biol. 199:1837-1844.

Feder, M. E., N. BLair, AND H. Figueras. 1997a. Natural thermal stress and heat-shock protein expression in Drosophila larvae and pupae. Funct. Ecol. 11:90-100.

__ 1997b. Thermal history of oviposition site does not alter oviposition site selection in Drosophila. Anim. Behav. 53:585588.

GU, X., AND A. J. ZERA. 1996. Quantitative genetics of juvenile hormone esterase, juvenile hormone binding and general esterase activity in the cricket Gryllus assimilis. Heredity 76:136-142.

GUPTA, R. S. 1990. Sequence and structural homology between a mouse T-complex protein TCP-1 and the "chaperonin" family of bacterial (GroEL, $60-65 \mathrm{kDa}$ heat shock antigen) and eukaryotic proteins. Biochem. Int. 20:833-841.

Hoffmann, A. A., AND P. A. Parsons. 1988. The analysis of quantitative variation in natural populations with isofemale strains. Genet. Sel. Evol. 20:87-98.

_ 1991. Evolutionary genetics and environmental stress. Oxford Univ. Press, New York.

HOULE, D. 1991. Genetic covariance of fitness correlates: what genetic correlations are made of and why it matters. Evolution 45:630-648.

Ish-Horowicz, D., S. M. Pinchin, P. SChedL, T. S. ARTAVAnis, AND M. E. Mirault. 1979. Genetic and molecular analysis of the 
87A7 and $87 \mathrm{Cl}$ heat-inducible loci of $D$. melanogaster. Cell 18: 1351-1358.

Jones, J. S., J. A. Coyne, ANd L. Partridge. 1987. Estimation of the thermal niche of Drosophila melanogaster using a temperature sensitive mutation. Am. Nat. 130:83-90.

KIRKPATRICK, M. 1996. Genes and adaptation: a pocket guide to the theory. Pp. 125-146 in M. R. Rose and G. V. Lauder, eds. Adaptation. Academic Press, San Diego, CA.

Krebs, R. A., AND M. E. FedER. 1997a. Natural variation in the expression of the heat-shock protein Hsp70 in a population of Drosophila melanogaster, and its correlation with tolerance of ecologically relevant thermal stress. Evolution 51:173-179.

. 1997b. Deleterious consequences of Hsp70 overexpression in Drosophila melanogaster larvae. Cell Stress and Chaperones 2:60-71.

- 1997c. Tissue specific variation in Hsp70 expression and thermal damage in Drosophila melanogaster larvae. J. Exp. Biol. 200:2007-2015.

KREBS, R. A., AND V. LoEschCKE. 1995. Resistance to thermal stress in preadult Drosophila buzzatii: variation among populations and changes in relative resistance across life stages. Biol. J. Linn. Soc. 56:517-531.

. 1997. Estimating heritability in a threshold trait: heat shock tolerance in Drosophila buzzatii. Heredity 79:252-259.

LANDE, R. 1982. A quantitative genetic theory of life-history evolution. Ecology 63:607-615.

LATTER, B. D. H., AND J. C. Mulley. 1995. Genetic adaptation to captivity and inbreeding depression in small laboratory populations of Drosophila melanogaster. Genetics 139:255-266.

LeRoI, A. M., W. R. Chen, AND M. R. Rose. 1994. Long-term laboratory evolution of a genetic life-history trade-off in Drosophila melanogaster. 2. Stability of genetic correlations. Evolution 48:1258-1268.

LoeschCKe, V., R. A. KRebs, AND J. S. F. BARKeR. 1994. Genetic variation for resistance and acclimation to high temperature stress in Drosophila buzzatii. Biol. J. Linn. Soc. 52:83-92.

Loeschcke, V., R. A. Krebs, J. Dahlgaard, and P. Michalek. 1997. High temperature stress and the evolution of thermal resistance in Drosophila. Pp. 175-190 in R. Bijlsma and V. Loeschcke, eds. Stress, adaptation and evolution. Birkhäuser, Basel, Switzerland.

NUNNEY, L. 1996. The response to selection for fast larval development in Drosophila melanogaster and its effect on adult weight: an example of a fitness trade-off. Evolution 50:11931204.

Palter, K. B., M. Watanabe, L. Stinson, A. P. Mahowald, and E. A. CRAIG. 1986. Expression and localization of Drosophila melanogaster hsp70 cognate proteins. Mol. Cell Biol. 6:11871203.

PARSONS, P. A. 1996. Stress, resources, energy balances, and evolutionary change. Evol. Biol. 29:39-72.

PARTRIDGE, L., AND M. FARQUHAR. 1983. Lifetime mating success of male fruit flies (Drosophila melanogaster) is related to their size. Anim. Behav. 31:871-877.

PARTRIDGe, L., AND K. Fowler. 1992. Direct and correlated responses to selection on age at reproduction in Drosophila melanogaster. Evolution 46:76-91.

PEASE, C. M., AND J. J. BUlL. 1988. A critique of methods for measuring life-history trade-offs. J. Evol. Biol. 1:293-303.

Pigliucci, M. 1996. Modeling phenotypic plasticity. II. Do genetic correlations matter? Heredity 77:453-460.

REEVE, E. C. R., AND F. W. Robertson. 1953. Studies in quantitative inheritance. II. Analysis of a strain of Drosophila melanogaster selected for long wings. J. Genet. 51:276-316.

RICE, W. R. 1989. Analyzing tables of statistical tests. Evolution 43:223-225.

Rose, M. R., AND B. Charlesworth. 1981. Genetics of life-history in Drosophila melanogaster. I. Sib analysis of adult females. Genetics 97:187-196.

SERVICE, P. M., AND M. R. Rose. 1985. Genetic covariation among life-history components: the effect of novel environments. Evolution 39:943-945.

StEaRnS, S. C. 1992. The evolution of life histories. Oxford Univ. Press, New York.

Welte, M. A., J. M. Tetrault, R. P. Dellavalle, and S. L. LindQUIST. 1993. A new method for manipulating transgenes: engineering heat tolerance in a complex, multicellular organism. Current Biol. 3:842-853.

WRIGHT, S. 1931. Evolution in Mendelian populations. Genetics 16:97-159.

ZwaAn, B. J., R. Bulsma, And R. K. Koekstra. 1995. Artificial selection for development time in Drosophila melanogaster in relation to aging: direct and correlated responses. Evolution 49: 635-648. 